\title{
Identification and evaluation of the role of the manganese efflux protein in Deinococcus radiodurans
}

\author{
Hongxing Sun ${ }^{1}$, Guangzhi Xu', Hongdan Zhan', Huan Chen², Zongtao Sun ${ }^{1}$, Bing Tian', Yuejin Hua ${ }^{1 *}$
}

\begin{abstract}
Background: Deinococcus radiodurans accumulates high levels of manganese ions, and this is believed to be correlated with the radiation resistance ability of this microorganism. However, the maintenance of manganese ion homeostasis in D. radiodurans remains to be investigated.

Results: In this study, we identified the manganese efflux protein (MntE) in D. radiodurans. The null mutant of mntE was more sensitive than the wild-type strain to manganese ions, and the growth of the mntE mutant was delayed in manganese-supplemented media. Furthermore, there was a substantial increase in the in vivo concentration of manganese ions. Consistent with these characteristics, the mntE mutant was more resistant to $\mathrm{H}_{2} \mathrm{O}_{2}$, ultraviolet rays, and $\gamma$-radiation. The intracellular protein oxidation (carbonylation) level of the mutant strain was remarkably lower than that of the wild-type strain.
\end{abstract}

Conclusions: Our results indicated that $d r 1236$ is indeed a mntE homologue and is indispensable for maintaining manganese homeostasis in $D$. radiodurans. The data also provide additional evidence for the involvement of intracellular manganese ions in the radiation resistance of $D$. radiodurans.

\section{Background}

Deinococcus radiodurans is an extreme bacterium known for its resistance to ionizing radiation (IR), ultraviolet (UV) radiation, oxidative stress, and desiccation $[1,2]$. It has been reported that $D$. radiodurans can recover from exposure to $\gamma$-radiation at $15 \mathrm{kGy}$, a dose lethal to most life forms. IR can directly damage biomacromolecules and can also produce reactive oxygen species (ROS) that can indirectly attack both proteins and DNA $[3,4]$. Therefore, cellular defense against ROS-induced protein and DNA damage is proposed to be important to the radiation resistance of $D$. radiodurans [5].

Manganese plays an important role in the antioxidant systems of bacteria and can relieve the phenotypic deficit of sod-null Escherichia coli [6]. Interestingly, Daly and coworkers found that the $\mathrm{Mn} / \mathrm{Fe}$ ratio of most IR-

\footnotetext{
* Correspondence: yjhua@zju.edu.cn

${ }^{1}$ Key Laboratory for Nuclear-Agricultural Sciences of Chinese Ministry of Agriculture and Zhejiang Province, Institute of Nuclear-Agricultural Sciences, Zhejiang University, 310029, Hangzhou, PR China Full list of author information is available at the end of the article
}

resistant bacteria is higher than that of IR-sensitive bacteria. The group also found that $D$. radiodurans grown in manganese-deficient medium was relatively more sensitive to IR than the bacteria grown in manganese-containing medium, suggesting that the accumulation of intracellular manganese ions can protect proteins from ROS-induced damage and can help in the survival of $D$. radiodurans in extreme environments $[5,7,8]$.

Although manganese can improve cellular ROS resistance, excess manganese is toxic to cells. Thus, maintenance of the intracellular $\mathrm{Mn}$ concentration homoeostasis is a challenge. In bacteria, two main classes of manganese transporters have been identifiedNramp $\mathrm{H}+-\mathrm{Mn}^{2+}$ transporters and the ATP-binding cassette (ABC) $\mathrm{Mn}^{2+}$ permeases [9]. Recently, a manganese efflux system was identified in Streptococcus pneumoniae, and this was found to play important roles in host pathogenesis and $\mathrm{H}_{2} \mathrm{O}_{2}$ resistance [10]. Many genes involved in the maintenance of manganese ion homeostasis have been reported in $D$. radiodurans, such as dr1709, dr2523 [11], dr2539 [12], and dr0615 [13]. Therefore, it would be very interesting to determine
C Biomed Central 
whether $D$. radiodurans possesses a similar manganese efflux system.

In this study, we identified a manganese efflux gene (dr1236) in D. radiodurans and demonstrated that it plays an important role in maintaining the homeostasis of intracellular Mn. The null mutant $m n t E^{-}$was highly sensitive to manganese ions. When the intracellular level of manganese ions was increased by mutating dr1236, the mutant showed clearly enhanced resistance to oxidative stress. Our results also demonstrated that increased intracellular Mn levels could substantially suppress protein oxidation (carbonylation) in D. radiodurans exposed to $\mathrm{H}_{2} \mathrm{O}_{2}$, indicating that manganese transport and regulation may be involved in the cellular resistance of $D$. radiodurans to oxidative stress.

\section{Results and discussion}

\section{D. radiodurans encodes a putative manganese efflux} protein

By searching the D. radiodurans genome http://www. ncbi.nlm.nih.gov/, we identified a manganese efflux protein homologue that was annotated as the conserved hypothetical protein DR1236 based on its extensive sequence similarity ( $25 \%$ identity, $49 \%$ similarity) to the manganese efflux protein (sp1552) of Streptococcus pneumoniae [10]. Similar to most cation diffusion facilitator (CDF) proteins, DR1236 has six putative transmembrane domains (TMDs) http://www.ch.embnet.org/ software/TMPRED_form.html. The most conserved region of the CDF protein is the TMD region, which is probably involved in metal transfer [14]. Sequence alignment was performed with the CLUSTAL W program available on the EMBL web page http://www.ebi.ac.uk. The alignment Sp1552 and DR1236 revealed the presence of highly conserved sequences in metal transfer regions III and VI (Figure 1). Moreover, the DXXXD motif, which is conserved in the manganese efflux protein, was also present in DR1236 (224 DAGVD 230).

\section{mntE is essential for the manganese resistance of $D$. radiodurans}

To confirm the specific substrate and roles of DR1236 in $D$. radiodurans, the null mutant of $d r 1236$ ( $\left.m n t E^{-}\right)$and wild-type revertant $m n t E$ strains were constructed (Figure 2). Metals including manganese are essential yet potentially toxic to bacteria [15]. Supplementation with certain metal ions can inhibit the growth of an exporter system mutant $[16,17]$; therefore, this phenotype is used to verify certain mutants. In this study, wild-type R1 and $d r 1236$ $\left(m n t E^{-}\right)$were grown on TGY plates overlaid with discs saturated with $10 \mu \mathrm{L}$ of different metal ion solutions $(1 \mathrm{M})$ containing manganese, magnesium, cobalt, calcium, copper, zinc, nickel, or iron ions. As shown in Figure 3A/B, the growth of the $m n t E^{-}$mutant was strongly inhibited by the manganese ions, but the mutant grew normally in the presence of other cations. Moreover, the wild-type revertant showed a growth phenotype similar to that of R1, indicating that growth inhibition of the $m n t E^{-}$mutant was due to the interruption of $d r 1236$.

To further investigate the influence of manganese ions on the $m n t E^{-}$mutant, different concentrations of manganese ions were added to TGY medium, and the growth of the mntE mutant was measured (Figure 3C). The results showed that in comparison with R1, the growth of the $m n t E^{-}$mutant was clearly delayed in the presence of low concentrations of manganese ions. When the manganese concentration increased, the growth defect phenotype became more pronounced. This phenotype is similar to that observed in Rosch's study in which the growth of S. pneumoniae having a disrupted calcium efflux system was more severely inhibited at higher calcium concentrations [18].

\section{The mntE- mutant shows high intracellular manganese concentrations}

To confirm that the $m n t E^{-}$mutant had lost its ability to export manganese ions, the intracellular manganese ion levels of wild-type R1 and the $m n t E^{-}$mutant were measured by inductively coupled plasma-mass spectrometry (ICP-MS). As expected, when grown on TGY medium supplemented with manganese ions, the manganese ion level in the mntE- mutant was almost four-fold higher than that in wild-type R1. However, there was no significant difference in the intracellular Fe ion concentrations of $\mathrm{R} 1$ and the mutant (Figure 4A). Similar results were obtained when the $m n t E^{-}$mutant and wild-type R1 were grown on TGY medium (Figure 4B). This result indicates that Dr1236 is a manganese ion exporter.

\section{The mntE' mutant shows higher resistance to $\gamma$-radiation,} UV, and oxidative

Recently, there has been a debate on whether the high intracellular $\mathrm{Mn} / \mathrm{Fe}$ ratio of $D$. radiodurans contributes to the extreme oxidative resistance of this microorganism. Daly et al proposed that the high $\mathrm{Mn} / \mathrm{Fe}$ ratio can effectively suppress protein carbonylation and increase radiation resistance $[7,8]$. In contrast, Sukhi et al and Shashidhar et al argued that $D$. radiodurans exhibits the same radiation resistance even when the intracellular $\mathrm{Mn} / \mathrm{Fe}$ ratio changed substantially $[19,20]$. Since the intracellular manganese ion level was significantly increased, a cell survival experiment was carried out to confirm whether the high intracellular manganese ion level could contribute to cellular resistance. The $D_{10}$ value represents the irradiating dose required to reduce the population by $90 \%$. Here, the $D_{10}$ value was proposed to assess the resistant ability of R1 and $m n t E^{-}$ mutant to different stresses. As shown in Figure 5 the 


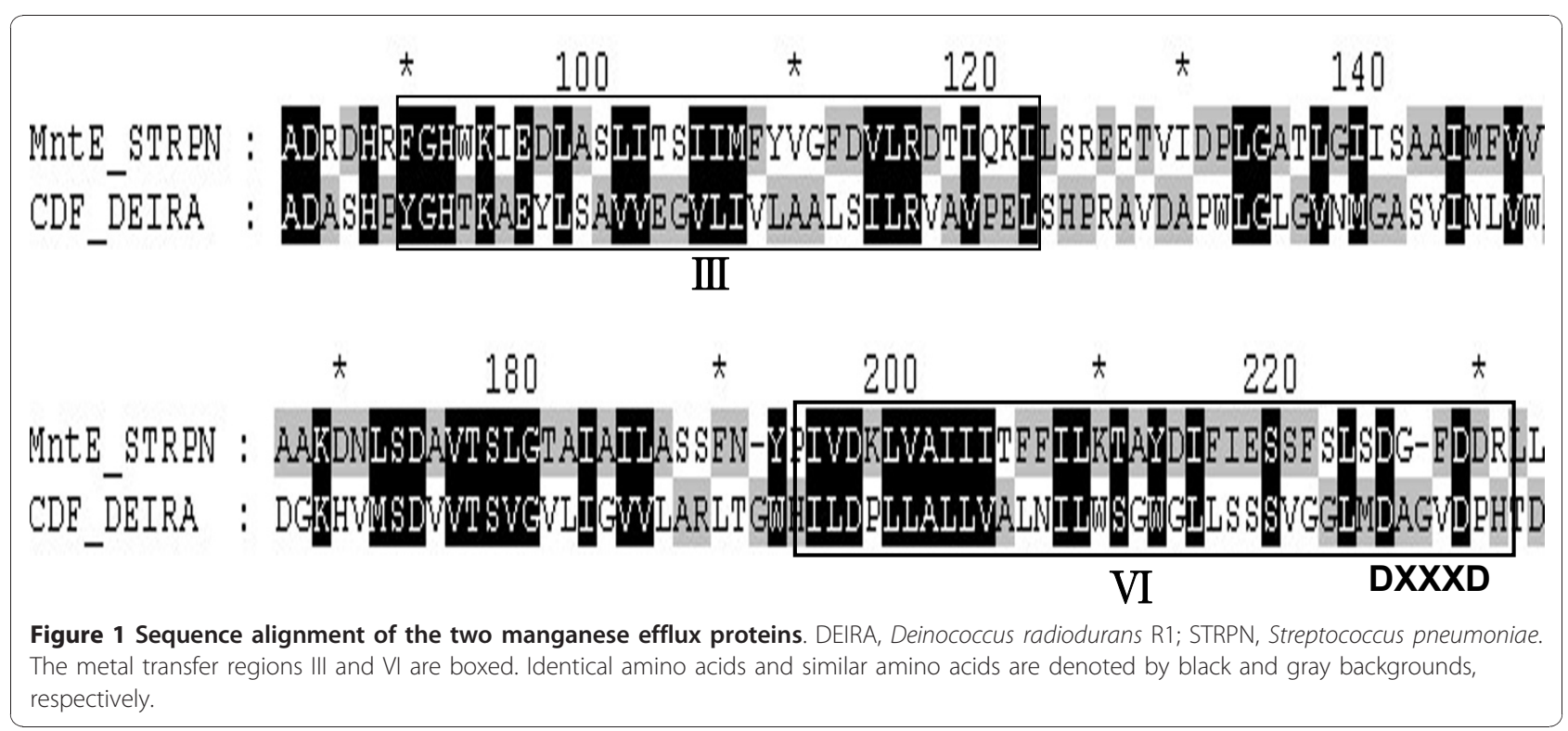

resistance of the $m n t E^{-}$mutant under different stresses was higher than that of $\mathrm{R} 1$, and the $\mathrm{D}_{10}$ values of the $m n t E^{-}$mutant were 14000 Gy $\gamma$-radiation, $700 \mathrm{~J} / \mathrm{m}^{2} \mathrm{UV}$, and $50 \mathrm{mM} \mathrm{H}_{2} \mathrm{O}_{2}$, whereas that for R1 was 11000 Gy $\gamma$ radiation, $600 \mathrm{~J} / \mathrm{m}^{2} \mathrm{UV}$, and $40 \mathrm{mM} \mathrm{H}_{2} \mathrm{O}_{2}$. Moreover, when R1 and $m n t E^{-}$mutant were cultured in TGY supplemented with $50 \mu \mathrm{M}$ manganese, their resistance to different stresses also increased remarkably, and it is consistent with their intracellular manganese level (Figure 5). The results suggest that there is a correlation between the intracellular manganese level and cellular oxidative resistance, which is consistent with the data from Daly's studies [8]. Although the role of manganese in the oxidative resistance of $D$. radiodurans remains
A

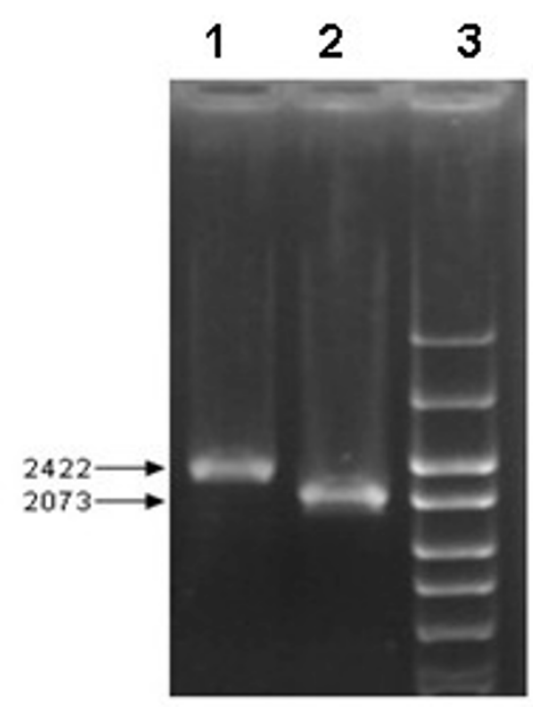

\section{B}

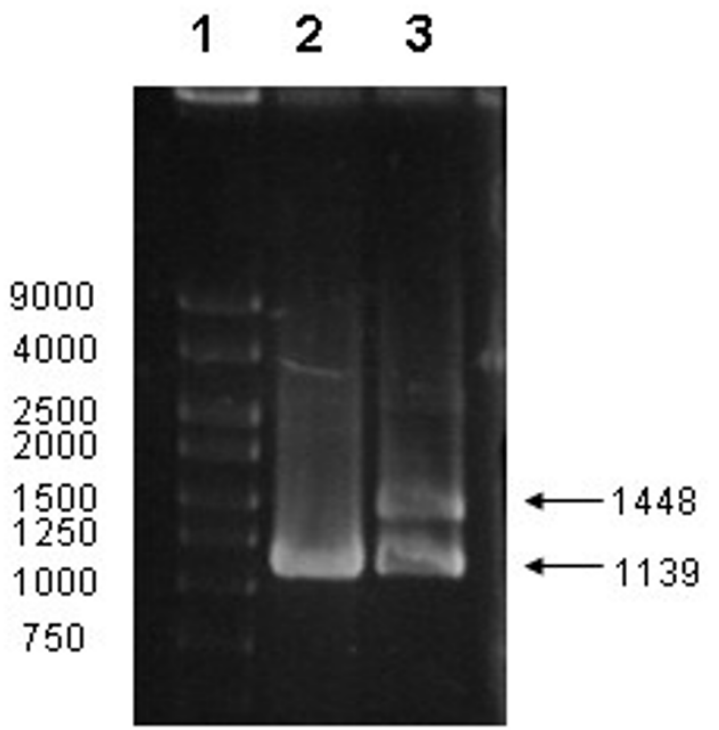

Figure 2 mntE mutant construction and verification by PCR. (A) Ethidium-bromide-stained agarose gel illustrating that the mutant carries a homozygous deletion of dr1236::aadA. Lane 1, mntE mutant; lane 2, R1; lane 3, DNA marker. Primers M1/M4 were used for PCR. (B) Verification of wild-type revertant mntE by PCR. Lane 1, DNA marker; lane 2, R1; lane 3, revertant mntE. Primers M5/M6 were used for PCR. 


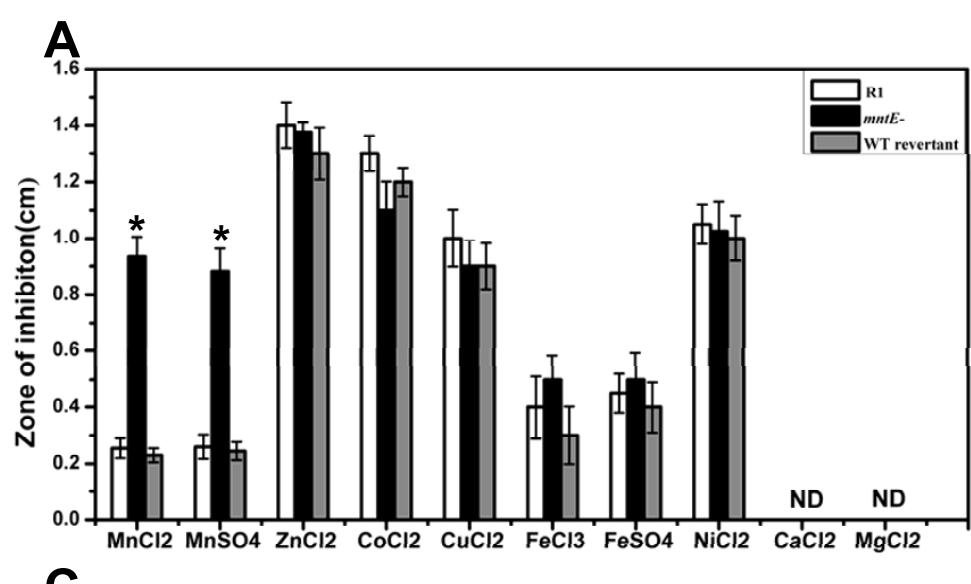

\section{B}

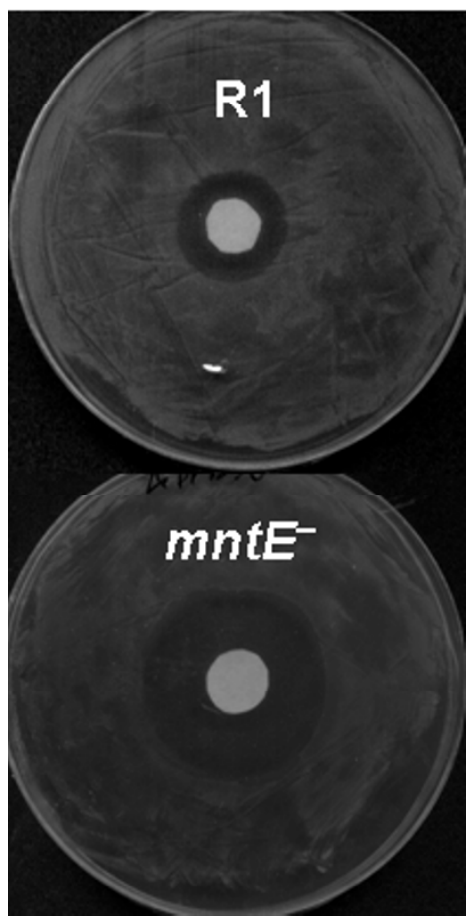

Figure 3 Manganese sensitivity assay for wild-type R1 and the mntE mutant. (A) Wild-type R1 (white bars), mntE (black bars), and WT revertant (gray bars) were cultured on TGY plates overlaid with filter discs saturated with $1 \mathrm{M}$ solutions of various cations. The zone of inhibition was measured from the edge of the disc after three days. ${ }^{*} P<0.01$. ND, not determined. (B) The inhibition zone of R1 and $m n t E$. Cells were cultured on TGY plates overlaid with filter discs saturated with $1 \mathrm{M}$ manganese chloride. (C) Wild-type R1 and mntE were inoculated in TGY supplemented with different concentrations of manganese chloride. The $\mathrm{OD}_{600}$ values were determined after $12 \mathrm{~h}$. Data represent the means \pm standard deviations of three independent experiments.

unclear, our study implies that an increase in the intracellular manganese level may be one of the responses to oxidative stress. Moreover, it is notable that the UV resistance of the $m n t E$ mutant also increased. Generally, UV light results in DNA damage, and only high doses of UV cause oxidative damage. Therefore, it is interesting to speculate that the UV resistance of the $m n t E^{-}$mutant may be indirectly enhanced by manganese ions. In fact, many important DNA repair enzymes use $\mathrm{Mn}^{2+}$ as the cofactor [21], and manganese accumulation may have a positive effect on gene function. Furthermore, a high intracellular manganese level is also known to have an important effect on the expression of many genes including stress response genes [10].

The $\mathrm{mntE}^{-}$mutant shows a lower protein oxidation level under oxidative stress

The protein carbonylation level is an important index of intracellular oxidative damage to proteins [8]. Previous reports have shown that the proteins of IR-sensitive bacteria are more vulnerable than those of $D$. radiodurans to ROS-induced protein oxidative damage [7]. Therefore, we measured and compared the levels of protein carbonylation in the $m n t E^{-}$mutant and wild-type R1. Notably, the level of protein carbonylation in the $m n t E^{-}$ mutant decreased to nearly $50 \%$ of that in R 1 after $\mathrm{H}_{2} \mathrm{O}_{2}$ treatment (Figure 6), indicating that the mutation of $m n t E$ resulted in a lower level of protein oxidation than that observed in the wild type. This suggests that the high level of intracellular manganese ions could enhance cellular resistance by protecting proteins against ROS damage.

\section{Conclusions}

Although it is known that the $\mathrm{Mn} / \mathrm{Fe}$ ratio of $D$. radiodurans is higher than that of other bacteria, little is known regarding the maintenance of the intracellular manganese ion level in this bacterium. So far, only one manganese efflux system has been identified in bacteria [10], and it is still unknown whether this system exists in $D$. radiodurans [22]. In this study, we identified a MntE homolog in D. radiodurans. As expected, our 


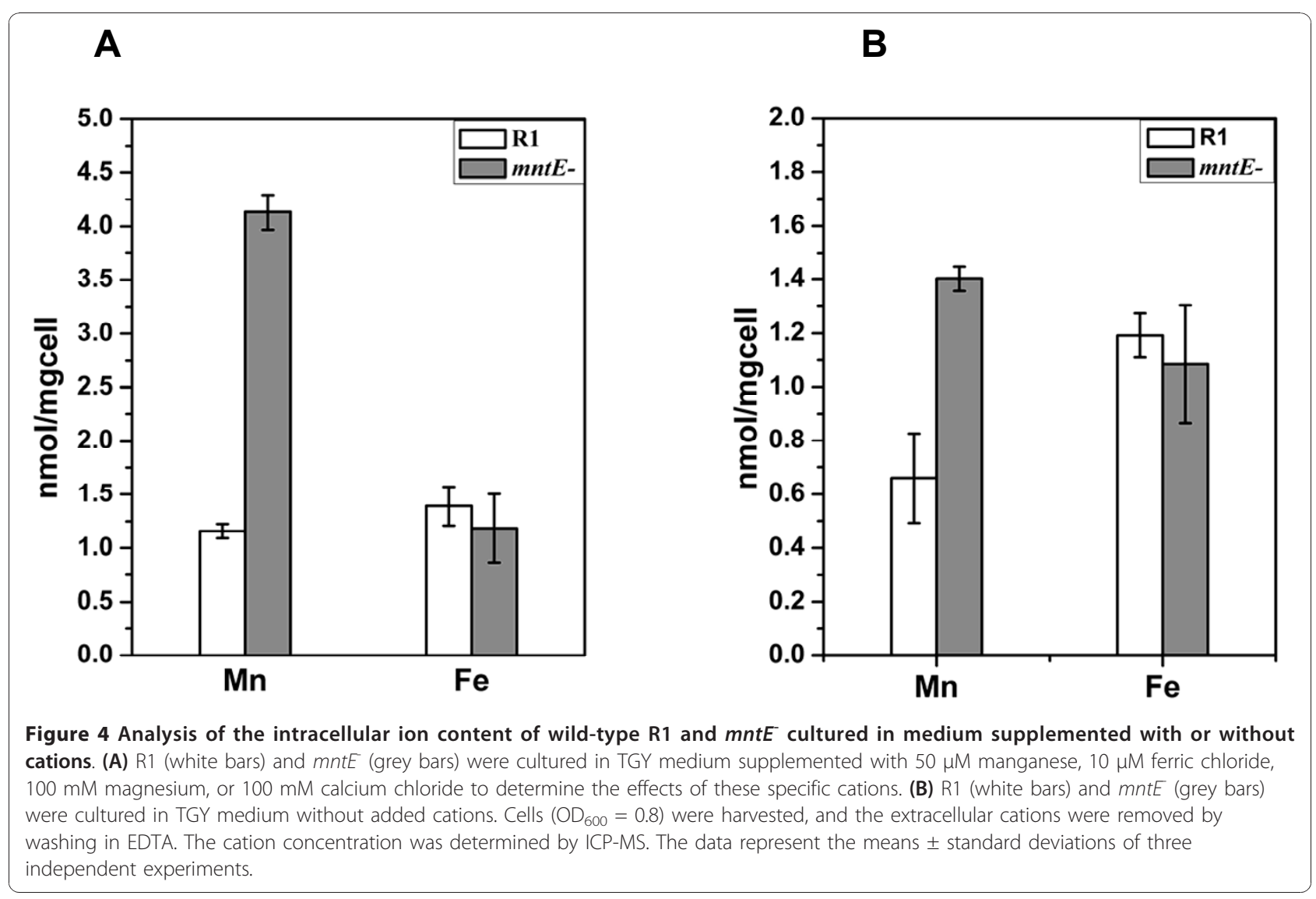

results showed that the intracellular manganese ion level was almost four-fold higher in the mutant than in $\mathrm{R} 1$. Furthermore, we also found that the oxidative level of $m n t E^{-}$proteins decreased to almost one half that of R1. On the other hand, the data also revealed that manganese accumulation is dangerous to the $m n t E^{-}$mutant. Based on these data, we conclude that $d r 1236$ is indeed a $m n t E$ homologue and is indispensable for maintaining manganese homeostasis in D. radiodurans. The results provide additional evidence that intracellular manganese ions are involved in the radiation resistance of $D$. radiodurans. However, because the intracellular $\mathrm{Mn} / \mathrm{Fe}$ ratio and the Mn concentration of $m n t E^{-}$both increased in this study, we could not clarify whether the $\mathrm{Mn} / \mathrm{Fe}$ ratio or the Mn concentration is more important for stress tolerance. Therefore, global analysis of the regulation of the intracellular manganese ion level is necessary in further studies.

\section{Methods}

\section{Strains and media}

All the strains and plasmids used in this study are listed in the supporting information (Table 1 ). The $D$. radiodurans strains were cultured at $30^{\circ} \mathrm{C}$ in TGY $(0.5 \%$ Bacto tryptone, $0.1 \%$ glucose, and $0.3 \%$ Bacto yeast extract) medium with aeration or on TGY plates supplemented with 1.2\% Bacto agar.

\section{Disruption and complementation of dr1236}

The mutant $d r 1236$ gene was constructed as described previously [23]. Briefly, 600-bp DNA fragments immediately upstream and downstream from $d r 1236$ were amplified from the genome of the $\mathrm{R} 1$ strain using the primer pairs ME1/ME2 and ME3/ME4, respectively (Table 2). These two fragments were digested with $B a m \mathrm{HI}$ and HindIII, respectively, and cloned to the streptomycin-resistance DNA fragment from $p K a t$-aadA [24] pretreated with the same enzymes. The ligation product was transformed into $D$. radiodurans $\mathrm{R} 1$, and mutant colonies were selected on TGY plates containing $8 \mu \mathrm{g} / \mathrm{mL}$ streptomycin. Null mutants were confirmed by PCR and sequencing, and the resulting mutant was designated $m n t E^{-}$.

A complementary plasmid was constructed and transformed into the $m n t E^{-}$mutant as described previously [25]. Briefly, the $d r 1236$ gene with the NdeI and BamHI sites was amplified with primers ME5/ME6. The PCR product was ligated to the pMD18-T simple vector (Takara, JP), and the product was designated $p M D m n t E$. After digestion with $\mathrm{NdeI}$ and $\mathrm{BamHI}$, the target gene 
A

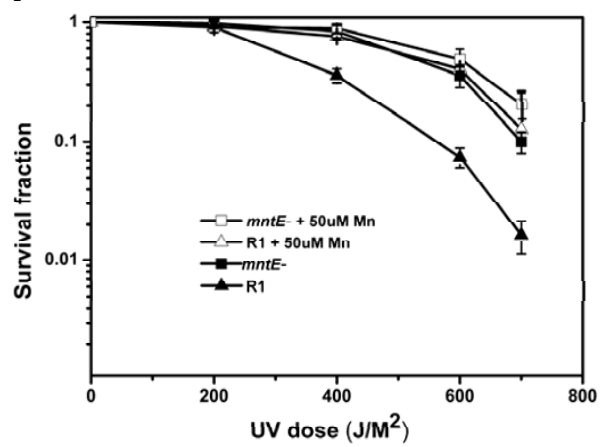

C

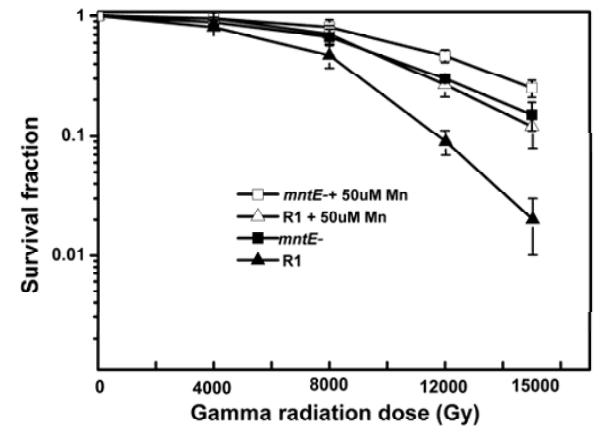

B

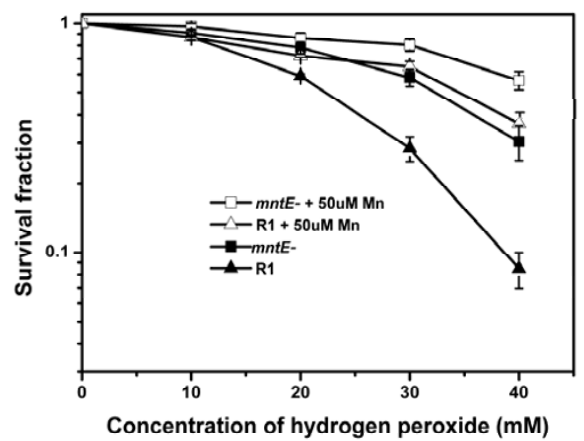

Figure 5 Survival curves for R1 (triangles) and mntE (squares) following exposure to UV (A), $\mathrm{H}_{2} \mathrm{O}_{2}$ (B), and $\boldsymbol{\gamma}$-radiation (C). R1 and $m n t E$ were cultured in TGY broth with or without $50 \mathrm{\mu M}$ manganese. The values represent the means \pm standard deviations of four independent experiments.

MntE was ligated to NdeI- and BamHI-predigested $p R A D K$ [23]. The complementation plasmid was confirmed by PCR and DNA sequence analyses and transformed into the $m n t E^{-}$strain.

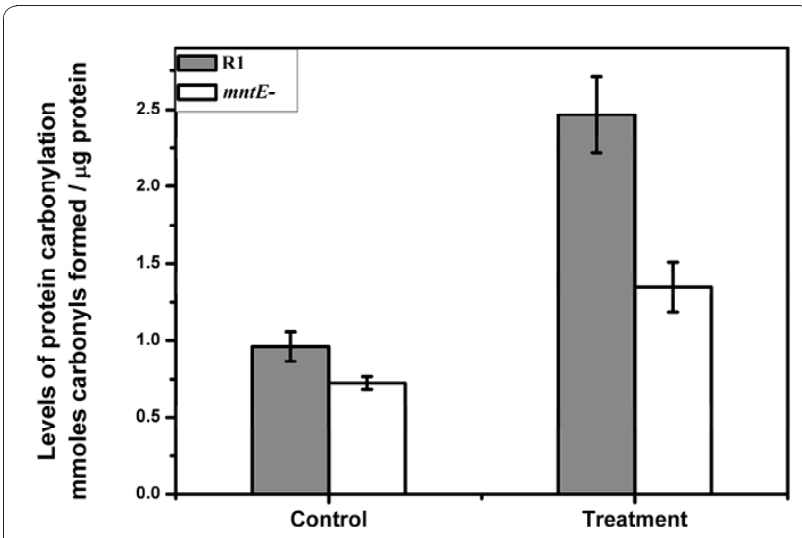

Figure 6 Protein carbonylation levels in R1 (black bars) and mntE (white bars). Cells $\left(\mathrm{OD}_{600}=0.8\right)$ were harvested and treated with $40 \mathrm{mM} \mathrm{H}_{2} \mathrm{O}_{2}$ for 30 min. The protein carbonylation levels were determined by the DNPH assay. Data represent the means \pm standard deviations of three independent experiments.

\section{Cation sensitivity assay}

Cation sensitivity assays were carried out as described previously [18]. Solutions (1 M) of manganese chloride, manganese sulfate, calcium chloride, magnesium chloride, zinc chloride, cobalt (II) chloride, copper chloride, ferric chloride, and ferrous sulfate (Sigma) were prepared in milli-Q water and filter-sterilized by passing through $0.22-\mu \mathrm{m}$ filters. Cells grown to the early stationary phase in TGY broth were plated on TGY plates and overlaid with $5-\mathrm{mm}$ sterile filter discs containing $10 \mu \mathrm{L}$ of various cation solutions. The plates were incubated for three days, and the inhibition zone of each disc was measured.

To measure the growth of $m n t E^{-}$and R1, $1 \times 10^{5} \mathrm{cfu}$ $\mathrm{mL}^{-1}$ were grown in TGY supplemented with increasing concentrations of $\mathrm{MnCl}_{2}$. The $\mathrm{OD}_{600}$ value was measured $12 \mathrm{~h}$ post incubation (mean $\pm \mathrm{SD}$ of three experiments).

\section{Inductively coupled plasma-mass spectrometry (ICP-MS)} assay

For the ICP-MS assays [26], the cells were cultured in TGY broth that had been pretreated with Chelex (Sigma) to remove any cations and supplemented with 
Table 1 Strains and plasmids used in this study

\begin{tabular}{|c|c|c|}
\hline Strain or plasmid & Relevant marker & Reference or resource \\
\hline \multicolumn{3}{|l|}{ Strains } \\
\hline E. coli DH5 $\alpha$ & hsdR17 recA1 endA1 lacZMM15 & Invitrogen \\
\hline D. radiodurans $\mathrm{R} 1$ & ATCC13939 & \\
\hline mntE & As R1, but mnE::aadA & This study \\
\hline$m n t R$ & As mntE mnE::aadA(pME $\left.m n t E_{D r}^{+}\right)$ & This study \\
\hline \multicolumn{3}{|l|}{ Plasmids } \\
\hline pMD18-T & TA cloning vector & Takara \\
\hline pRADK & E. coli-D. radiodurans shuttle vector carrying D. radiodurans groEL promoter & {$[27]$} \\
\hline pME & pRADK derivative expressing $D$. radiodurans mntE & This study \\
\hline
\end{tabular}

$50 \mu \mathrm{M}$ manganese, $10 \mu \mathrm{M}$ ferric chloride, $100 \mathrm{mM}$ magnesium, or $100 \mathrm{mM}$ calcium chloride. Cells $\left(\mathrm{OD}_{600}=\right.$ 0.6-0.8) were harvested by centrifugation, washed three times with phosphate-buffered saline (PBS) containing $10 \mathrm{mM}$ EDTA, and rinsed three times with PBS without EDTA. Cells (1/10 of the total volume) were withdrawn to measure the dry weight, and the remaining cells were treated with nitric acid and used for the ICP-MS assay.

\section{Survival curves of the mntE mutant and R1}

R1 and $m n t E^{-}$cells were cultured in TGY broth with or without $50 \mu \mathrm{M}$ manganese to $\mathrm{OD}_{600}=1.0$, centrifuged, and then resuspended in phosphate buffer. For the $\gamma$ irradiation treatment, the suspension was irradiated with different doses of ${ }^{60} \mathrm{Co} \gamma$-radiation for $1 \mathrm{~h}$ on ice. After the irradiation treatment, the cells were plated on TGY plates and incubated at $30^{\circ} \mathrm{C}$ for three days. The colonies were then counted. For the UV treatment, the cells were plated on TGY plates and exposed to different doses of UV radiation at $254 \mathrm{~nm}$. For the $\mathrm{H}_{2} \mathrm{O}_{2}$ treatment, the cultures were treated with different concentrations of $\mathrm{H}_{2} \mathrm{O}_{2}$ for $30 \mathrm{~min}$ and then plated on TGY plates.

\section{Protein carbonylation assay}

Cells grown to $\mathrm{OD}_{600}=0.5$ were treated with $\mathrm{H}_{2} \mathrm{O}_{2}(30$ $\mathrm{mM})$, harvested, and resuspended in PBS containing 1\% (by volume) $\beta$-mercaptoethanol and $1 \mathrm{mM}$ phenylmethanesulfonyl fluoride. The cells were disrupted by

Table 2 Primers used in this study

\begin{tabular}{ll}
\hline Primer Sequence & $\left(\mathbf{5}^{\prime} \boldsymbol{\rightarrow} \mathbf{3} \mathbf{3}^{\prime}\right)$ \\
\hline Construction of the mntE mutant \\
ME1 & GCACGCGCTITCCTATGAC \\
ME2 & ATATGGATCCACCACCGCACTGAGGTATTC \\
ME3 & ATATAAGCTCCGGCGCCAACGTCACCATT \\
ME4 & CGCCGACCAGGACACGATAG \\
Complementation of the mntE mutant \\
ME5 \\
ME6 \\
\hline
\end{tabular}

sonication, and the cell-free extracts were used for the protein carbonylation assay. The protein concentrations were determined by the Bradford method. The cell-free extracts were incubated with $400 \mu \mathrm{L}$ of $10 \mathrm{mM} \mathrm{2,4-}$ dinitrophenyl hydrazine (DNPH) in $2 \mathrm{M} \mathrm{HCl}$ for $2 \mathrm{~h}$ in the dark. After precipitation with ice-chilled 10\% trichloroacetic acid (TCA), the precipitated proteins were washed three times with $50 \%$ ethyl acetate in ethanol. The decolorized precipitates were evaporated and dissolved in $1 \mathrm{~mL}$ of $6 \mathrm{M}$ guanidine hydrochloride. The solution was centrifuged, and the absorbance of the supernatant was determined at $370 \mathrm{~nm}$ against a protein control that had been processed in parallel but with 2 $\mathrm{M} \mathrm{HCl}$ instead of DNPH. The protein carbonyl content is defined as $\mathrm{mM} / \mathrm{mg}$ protein.

\section{Statistical analysis}

Student's $t$-test was used to assess the significance between results, and $p<0.05$ was considered as significant.

\section{Acknowledgements}

This work was supported by a grant from the National Basic Research Program of China (2007CB707804), a grant from the National Hi-Tech Development Program (2007AA021305), a key project of the National Natural Science Foundation of China (30830006), a major scientific and technological project for significant new drugs creation (2009ZXJ09001-034), a major project for genetically modified organisms breeding (2009ZX08009075B), a grant from the National Natural Science Foundation of China (30870035), the project "Application of Nuclear Techniques in Agriculture" from the Chinese Ministry of Agriculture (200803034), and a grant from Zhejiang Provincial Natural Science Foundation (Y3090032).

\section{Author details}

${ }^{1}$ Key Laboratory for Nuclear-Agricultural Sciences of Chinese Ministry of Agriculture and Zhejiang Province, Institute of Nuclear-Agricultural Sciences, Zhejiang University, 310029, Hangzhou, PR China. ${ }^{2}$ Zhejiang Institute of Microbiology, Zhejiang Province, Hangzhou, 310012, PR China.

\section{Authors' contributions}

HXS and YJH conceived and designed the study. HXS performed the experiments and wrote the manuscript. GZX, BT and HC participated in the discussion of the experimental results. HDZ and ZTS carry out the protein carbonylation analysis. All authors read and approved the final manuscript.

Received: 9 June 2010 Accepted: 14 December 2010

Published: 14 December 2010 


\section{References}

1. Rainey FA, Nobre MF, Schumann P, Stackebrandt E, da Costa MS Phylogenetic diversity of the deinococci as determined by $16 \mathrm{~S}$ ribosomal DNA sequence comparison. Int J Syst Bacteriol 1997, 47:510-514

2. Battista JR, Earl AM, Park MJ: Why is Deinococcus radiodurans so resistant to ionizing radiation? Trends Microbiol 1999, 7:362-365.

3. Goswami M, Mangoli SH, Jawali N: Involvement of reactive oxygen species in the action of ciprofloxacin against Escherichia coli. Antimicrob Agents Chemother 2006, 50:949-954

4. Repine JE, Pfenninger OW, Talmage DW, Berger EM, Pettijohn DE: Dimethyl sulfoxide prevents DNA nicking mediated by ionizing radiation or iron/ hydrogen peroxide-generated hydroxyl radical. Proc Natl Acad Sci USA 1981, 78:1001-1003.

5. Daly MJ: A new perspective on radiation resistance based on Deinococcus radiodurans. Nat Rev Microbiol 2009, 7:237-245.

6. Al-Maghrebi M, Fridovich I, Benov L: Manganese supplementation relieves the phenotypic deficits seen in superoxide-dismutase-null Escherichia coli. Arch Biochem Biophys 2002, 402:104-109.

7. Daly MJ, Gaidamakova EK, Matrosova VY, Vasilenko A, Zhai M, Leapman RD, Lai B, Ravel B, Li S-MW, Kemner KM, Fredrickson JK: Protein Oxidation Implicated as the Primary Determinant of Bacterial Radioresistance. PLoS Biol 2007, 5:e92.

8. Daly MJ, Gaidamakova EK, Matrosova VY, Vasilenko A, Zhai M, Venkateswaran A, Hess M, Omelchenko MV, Kostandarithes HM, Makarova KS, et al: Accumulation of $\mathrm{Mn}$ (II) in Deinococcus radiodurans facilitates gamma-radiation resistance. Science 2004, 306:1025-1028.

9. Papp-Wallace KM, Maguire ME: Manganese transport and the role of manganese in virulence. Annu Rev Microbiol 2006, 60:187-209.

10. Rosch JW, Gao G, Ridout G, Wang YD, Tuomanen El: Role of the manganese efflux system mntE for signalling and pathogenesis in Streptococcus pneumoniae. Mol Microbiol 2009, 72:12-25.

11. Chang S, Shu H, Li Z, Wang Y, Chen L, Hua Y, Qin G: Disruption of manganese ions $[\mathrm{Mn}(\mathrm{II})]$ transporter genes DR1709 or DR2523 in extremely radio-resistant bacterium Deinococcus radiodurans. Wei Sheng Wu Xue Bao 2009, 49:438-444.

12. Chen H, Wu R, Xu G, Fang X, Qiu X, Guo H, Tian B, Hua Y: DR2539 is a novel DtxR-like regulator of $\mathrm{Mn} / \mathrm{Fe}$ ion homeostasis and antioxidant enzyme in Deinococcus radiodurans. Biochem Biophys Res Commun 2010 396:413-418.

13. Chen H, Xu G, Zhao Y, Tian B, Lu H, Yu X, Xu Z, Ying N, Hu S, Hua Y: A novel OxyR sensor and regulator of hydrogen peroxide stress with one cysteine residue in Deinococcus radiodurans. PLoS One 2008, 3:e1602.

14. Haney CJ, Grass G, Franke S, Rensing C: New developments in the understanding of the cation diffusion facilitator family. J Ind Microbiol Biotechnol 2005, 32:215-226.

15. Kehres DG, Maguire ME: Emerging themes in manganese transport, biochemistry and pathogenesis in bacteria. FEMS Microbiol Rev 2003, 27:263-290.

16. Kloosterman TG, van der Kooi-Pol MM, Bijlsma JJ, Kuipers OP: The novel transcriptional regulator SczA mediates protection against $\mathrm{Zn} 2+$ stress by activation of the $\mathrm{Zn2+-resistance} \mathrm{gene} \mathrm{CzcD}$ in Streptococcus pneumoniae. Mol Microbiol 2007, 65:1049-1063.

17. McAllister $L J$, Tseng HJ, Ogunniyi AD, Jennings MP, McEwan AG, Paton JC: Molecular analysis of the psa permease complex of Streptococcus pneumoniae. Mol Microbiol 2004, 53:889-901.

18. Rosch JW, Sublett J, Gao G, Wang YD, Tuomanen El: Calcium efflux is essential for bacterial survival in the eukaryotic host. Mol Microbiol 2008, 70:435-444.

19. Sukhi SS, Shashidhar R, Kumar SA, Bandekar JR: Radiation resistance of Deinococcus radiodurans $\mathrm{R} 1$ with respect to growth phase. FEMS Microbiol Lett 2009, 297:49-53.

20. Shashidhar R, Kumar SA, Misra HS, Bandekar JR: Evaluation of the role of enzymatic and nonenzymatic antioxidant systems in the radiation resistance of Deinococcus. Can J Microbiol 56:195-201.

21. Blasius $M$, Shevelev I, Jolivet $E$, Sommer $S$, Hubscher U: DNA polymerase $X$ from Deinococcus radiodurans possesses a structure-modulated $3^{\prime}->5^{\prime}$ exonuclease activity involved in radioresistance. Mol Microbiol 2006, 60:165-176.

22. Hua S, Shenghe C, Zongwei L, Yanping W, Guangyong Q: Functional analysis of a putative transcriptional regulator gene dr2539 in Deinococcus radiodurans. AFR J MICROBIOL RES 2010, 4:515-522.
23. Gao GJ, Lu HM, Huang LF, YJ H: Construction of DNA damage response gene pprl function deficient and function complementary mutants in Deinococcus radiodurans. Chin Sci Bull 2005, 50:311-316.

24. Tanaka M, Narumi I, Funayama T, Kikuchi M, Watanabe H, Matsunaga T, Nikaido O, Yamamoto K: Characterization of pathways dependent on the uvsE, uvrA1, or uvrA2 gene product for UV resistance in Deinococcus radiodurans. J Bacteriol 2005, 187:3693-3697.

25. Hua Y, Narumi I, Gao G, Tian B, Satoh K, Kitayama S, Shen B: Pprl: a general switch responsible for extreme radioresistance of Deinococcus radiodurans. Biochem Biophys Res Commun 2003, 306:354-360.

26. Ma JF, Ochsner UA, Klotz MG, Nanayakkara VK, Howell ML, Johnson Z, Posey JE, Vasil ML, Monaco JJ, Hassett DJ: Bacterioferritin A modulates catalase $A(K a t A)$ activity and resistance to hydrogen peroxide in Pseudomonas aeruginosa. J Bacteriol 1999, 181:3730-3742.

27. Huang L, Hua X, Lu H, Gao G, Tian B, Shen B, Hua Y: Three tandem HRDC domains have synergistic effect on the RecQ functions in Deinococcus radiodurans. DNA Repair (Amst) 2007, 6:167-176.

doi:10.1186/1471-2180-10-319

Cite this article as: Sun et al.: Identification and evaluation of the role of the manganese efflux protein in Deinococcus radiodurans. BMC Microbiology 2010 10:319.

\section{Submit your next manuscript to BioMed Central and take full advantage of:}

- Convenient online submission

- Thorough peer review

- No space constraints or color figure charges

- Immediate publication on acceptance

- Inclusion in PubMed, CAS, Scopus and Google Scholar

- Research which is freely available for redistribution

Submit your manuscript at www.biomedcentral.com/submit
C Biomed Central 